University of Wollongong

Research Online

Faculty of Engineering - Papers (Archive)

Faculty of Engineering and Information

Sciences

$1-1-2010$

\title{
Nanocoating of particles for optimal doping and universal enhancement of current-carrying ability in "organic" MgB2-xCx superconductors
}

Olga V. Shcherbakova

University of Wollongong, olga@uow.edu.au

Alexey V. Pan

University of Wollongong, pan@uow.edu.au

S X. Dou

University of Wollongong, shi@uow.edu.au

Rashmi Nigam

University of Wollongong, rnigam@uow.edu.au

David Wexler

University of Wollongong, david_wexler@uow.edu.au

Follow this and additional works at: https://ro.uow.edu.au/engpapers

Part of the Engineering Commons

https://ro.uow.edu.au/engpapers/3106

\section{Recommended Citation}

Shcherbakova, Olga V.; Pan, Alexey V.; Dou, S X.; Nigam, Rashmi; and Wexler, David: Nanocoating of particles for optimal doping and universal enhancement of current-carrying ability in "organic" $\mathrm{MgB2}-\mathrm{xCx}$ superconductors 2010, 09E147-1-09E147-3.

https://ro.uow.edu.au/engpapers/3106

Research Online is the open access institutional repository for the University of Wollongong. For further information contact the UOW Library: research-pubs@uow.edu.au 


\section{AIP $\mid$ Appilied Physics}

\section{Nanocoating of particles for optimal doping and universal enhancement of current-carrying ability in "organic" MgB2-xCx superconductors}

O. V. Shcherbakova, A. V. Pan, S. X. Dou, R. Nigam, and D. Wexler

Citation: J. Appl. Phys. 107, 09E147 (2010); doi: 10.1063/1.3366610

View online: http://dx.doi.org/10.1063/1.3366610

View Table of Contents: http://jap.aip.org/resource/1/JAPIAU/v107/i9

Published by the American Institute of Physics.

\section{Related Articles}

Possibility of a (bi)polaron high-temperature superconductivity in Poly A/ Poly T DNA duplexes

J. Appl. Phys. 112, 064701 (2012)

Strain-induced superconductor/insulator transition and field effect in a thin single crystal of molecular conductor Appl. Phys. Lett. 92, 243508 (2008)

Superconductivity and antiferromagnetism in quasi-one-dimensional organic conductors (Review Article) Low Temp. Phys. 32, 380 (2006)

Incoherent interlayer electron hopping as a possible reason for enhanced magnetic quantum oscillations in the mixed state of a layered organic superconductor

Low Temp. Phys. 32, 109 (2006)

The essential role of hydrogen atoms in the electron-phonon interactions in the monocation of cubic hydrocarbon cluster, $(\mathrm{CH}) 8$

J. Chem. Phys. 118, 10073 (2003)

\section{Additional information on J. Appl. Phys.}

Journal Homepage: http://jap.aip.org/

Journal Information: http://jap.aip.org/about/about_the_journal

Top downloads: http://jap.aip.org/features/most_downloaded

Information for Authors: http://jap.aip.org/authors

\section{ADVERTISEMENT}

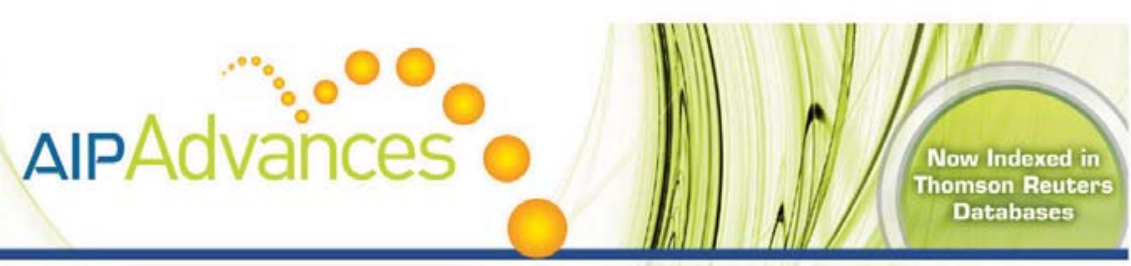

\section{Explore AIP's open access journal: •Rapid publication Article-level metrics \\ Post-publication rating and commenting}




\title{
Nanocoating of particles for optimal doping and universal enhancement of current-carrying ability in "organic" $\mathrm{MgB}_{2-x} \mathrm{C}_{x}$ superconductors
}

\author{
O. V. Shcherbakova, ${ }^{1, a)}$ A. V. Pan, ${ }^{1}$ S. X. Dou, ${ }^{1}$ R. Nigam, ${ }^{1}$ and D. Wexler ${ }^{2}$ \\ ${ }^{1}$ Institute for Superconducting and Electronic Materials, University of Wollongong, Northfields Avenue, \\ Wollongong, New South Wales 2522, Australia \\ ${ }^{2}$ School of Materials, Mechanical and Mechatronic Engineering, University of Wollongong, Northfields \\ Avenue, Wollongong, New South Wales 2522, Australia
}

(Presented 21 January 2010; received 31 October 2009; accepted 16 February 2010; published online 11 May 2010)

\begin{abstract}
The universal approach of liquid mixing has been found to produce "organic" $\mathrm{MgB}_{2-x} \mathrm{C}_{x}$ superconductors with structural and supercurrent-carrying properties unattainable by other techniques. We show by transmission electron microscopy combined with energy dispersive spectroscopy that these unique properties are enabled through coating of boron particles with a nanolayer of carbon. The subsequent reaction between carbon-encapsulated boron and magnesium results in enhanced carbon content $x$ in the crystal lattice, as determined by x-ray diffraction pattern analysis. Among various carbon-containing compounds investigated, polycarbosilane has been found to be the optimal dopant for $\mathrm{MgB}_{2}$ superconductor, producing the largest critical current density due to the formation of wide range of nanodefects with pinning properties within the $\mathrm{MgB}_{2}$ crystal lattice, as well as due to minimal formation of current-blocking layers around the grains. (C) 2010 American Institute of Physics. [doi:10.1063/1.3366610]
\end{abstract}

Superconductivity, with its zero-resistance below the critical temperature $T_{c}$ and its capacity to carry high supercurrents in some superconducting materials, enables unique high-current applications, for example, in medicine (superconducting magnets for magnetic resonance imaging). The middle range $T_{c}$ superconductor $\mathrm{MgB}_{2}$ discovered in 2001 (Ref. 1) is one of the most promising materials for these applications. Intensive studies of this superconductor have resulted in significant advances in understanding of currentcarrying performance at high magnetic fields. The key feature of the advanced performance is the conversion of $\mathrm{MgB}_{2}$ into "organic" $\mathrm{MgB}_{2-x} \mathrm{C}_{x}$ superconductor, ${ }^{2}$ which is relatively easily achievable via chemical doping with carbonbased compounds.

Nano-SiC has been shown to be one of the most effective dopants for enhancement of electromagnetic properties of $\mathrm{MgB}_{2}$ superconductor. $^{2-5}$ However, the critical current density $\left(J_{c}\right)$ enhancement achieved at high fields are usually associated with $J_{c}$ degradation in low fields due to stronger current carrier scattering and current-blocking effects on grain boundaries. ${ }^{6}$ The search for optimal conditions and new methods for converting $\mathrm{MgB}_{2}$ into $\mathrm{MgB}_{2-x} \mathrm{C}_{x}$ has led to a new advanced and, at the same time, simplified approach for the carbon-doping of $\mathrm{MgB}_{2}$ superconductor. We have dissolved, first, glucose $\left(\mathrm{C}_{6} \mathrm{H}_{12} \mathrm{O}_{6}\right)$ (Ref. 7) and then a range of other carbohydrates, such as malic acid $\left(\mathrm{C}_{4} \mathrm{H}_{6} \mathrm{O}_{5}\right),{ }^{8}$ in an appropriate solvent (water and toluene, respectively), and then mixed the particular carbon-containing solution with boron powder. This approach assumes extremely homogeneous mixing of raw components enabling enhanced perfor-

\footnotetext{
${ }^{a)}$ Electronic mail: olga@uow.edu.au.
}

mance of the final $\mathrm{MgB}_{2-x} \mathrm{C}_{x}$ superconductor. A reasonable assertion was made that the liquid mixing approach results in a coating of each boron particle with a nanolayer of carbon. ${ }^{7}$ However, no evidence for this has been provided so far. In this work, we indeed reveal the thin carbon plating on the surface of the boron precursor powder particles and clarify its role in the enhanced current-carrying ability.

To demonstrate the simplicity of our new approach, we employed table sugar (or sucrose, $\mathrm{C}_{12} \mathrm{H}_{22} \mathrm{O}_{11}$ ) as a cheap and readily available carbon dopant for $\mathrm{MgB}_{2}$ superconductor. To prove universality, we show that the liquid mixing approach can be extended to the group of polymer carbon-containing dopants. For this purpose, the effect of polycarbosilane $\left(\mathrm{C}_{2} \mathrm{H}_{6} \mathrm{Si}\right)$ doping has been investigated. The polycarbosilane is a polymer analog to nano-SiC doping, ${ }^{9}$ which is expected to combine the benefits of the liquid mixing of carbohydrates and the codoping with $\mathrm{C}$ and $\mathrm{Si}$, as it occurs in nano-SiC doping. 2,3

Pure and doped $\mathrm{MgB}_{2}$ bulk samples have been prepared using our new liquid mixing approach. ${ }^{7}$ To enable a comparative analysis, three dopants, table sugar $\left(\mathrm{C}_{12} \mathrm{H}_{22} \mathrm{O}_{11}\right)$, malic acid $\left(\mathrm{C}_{4} \mathrm{H}_{6} \mathrm{O}_{5}\right)$, and polycarbosilane $\left(\mathrm{C}_{2} \mathrm{H}_{6} \mathrm{Si}\right.$, PCS later in the text), have been added at the level of $10 \mathrm{wt} \%$. The sugar was dissolved in water while the malic acid and the PCS were dissolved in toluene $\left(\mathrm{C}_{7} \mathrm{H}_{8}\right)$. After the liquid mixing stage, samples were pressed into pellets, and then heat treated at $700{ }^{\circ} \mathrm{C}$ for $30 \mathrm{~min}$ in Ar atmosphere, followed by furnace cooling to room temperature.

The critical current density as a function of the applied magnetic field $\left(B_{a}\right)$ has been determined from magnetization measurements using the critical state model for the rectangular geometry of the samples. Transmission electron microscopy (TEM) has been carried out using a JOEL 2011200 


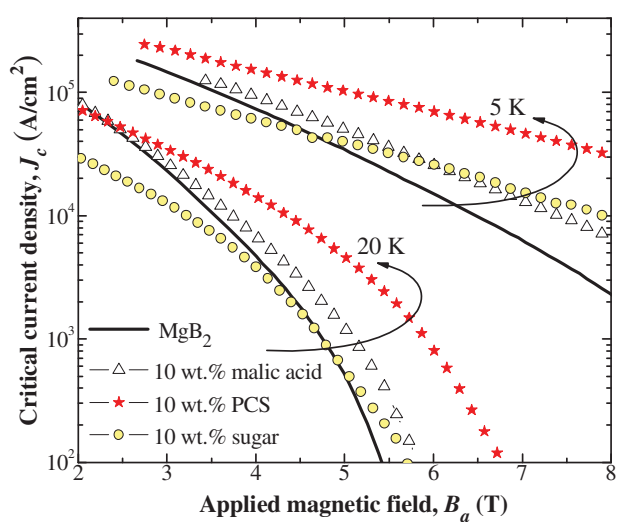

FIG. 1. (Color online) $J_{c}\left(B_{a}\right)$ of $\mathrm{MgB}_{2}$ samples with $10 \mathrm{wt} \%$ addition of malic acid, PCS, and sugar doping materials.

$\mathrm{KeV}$ analytical electron microscope with a JOEL energy dispersive X-ray spectroscopy (EDS) system. X-ray diffraction (XRD) patterns were obtained on a GBC Mini-Materials Analyser (MMA) x-ray diffractometer, whereas Rietveld refinement of XRD patterns has been used to analyze the crystal structure of the samples.

The liquid mixing of boron with carbon-based dopants resulted in the significant enhancement of the $J_{c}\left(B_{a}\right)$ for all the samples studied (Fig. 1), which is consistent with previous results. ${ }^{7,8}$ The observed improvement of $J_{c}\left(B_{a}\right)$ is due to the appearance of additional defects, which increase the upper critical field $\left(B_{c 2}\right)$ through enhanced electron scattering, and improve pinning of magnetic vortices on defects with the size of $\sim 2 \xi^{3-5,10-12}$ where $\xi$ is the coherence length. TEM investigations (Fig. 2) revealed that typical additional defects induced by doping are (i) crystal lattice defects--stacking faults and dislocations [Fig. 2(a)] and nanodomains [Fig. 2(b)], etc.--of $<10 \mathrm{~nm}$ produced by $\mathrm{C}$ substitution, and (ii) nanoscale impurities with sizes of $\leq 20 \mathrm{~nm}(\mathrm{MgO}$ in samples with carbohydrate doping; $\mathrm{MgO}$ and $\mathrm{Mg}_{2} \mathrm{Si}$ in the PCS doped sample) [Fig. 2(c)].

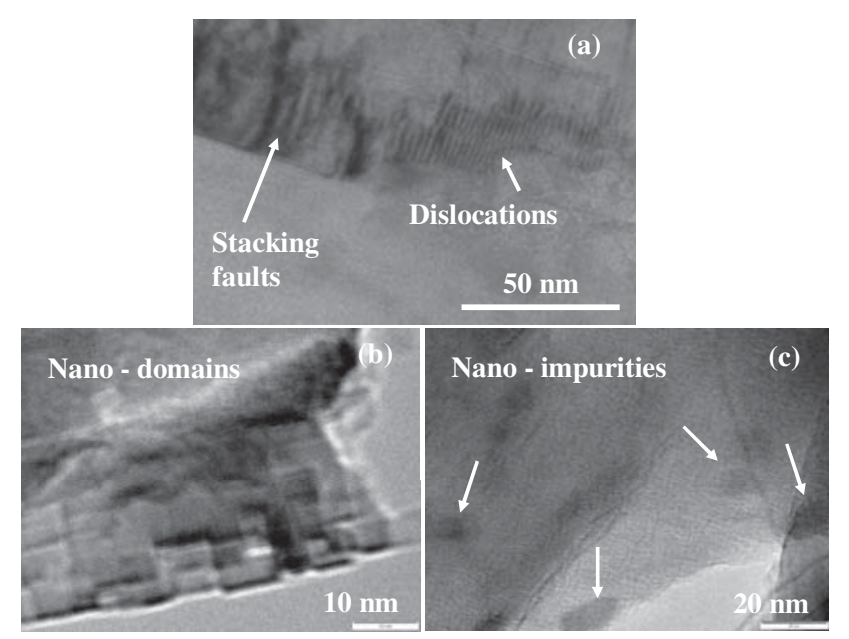

FIG. 2. Typical defects observed in C-doped $\mathrm{MgB}_{2}$ samples: (a) stacking faults and dislocations; (b) nanodomains of $<10 \mathrm{~nm}$ large size; (c) nanoscale impurities of $\leq 20 \mathrm{~nm}$ large.

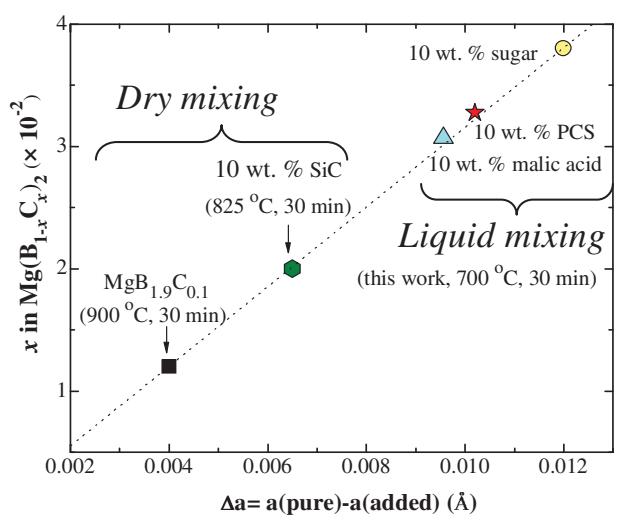

FIG. 3. (Color online) Level of $\mathrm{C}$ substitution $(x)$ for $\mathrm{B}$ in $\mathrm{MgB}_{2}$ lattice.

Generally, the crystal lattice is much more defective in doped than in pure $\mathrm{MgB}_{2}$, and hence $\xi$ is smaller (because $B_{c 2} \propto 1 / \xi^{2}$ is considerably larger). Therefore, defects with smaller sizes, such as type (i), which are less effective for pure samples with larger $\xi$, become effective pinning sites. This also explains the generally stronger enhancement of $J_{c}\left(B_{a}\right)$ for the doped samples at lower temperatures (Fig. 1), in which $\xi(T)$ is the smallest.

The $J_{c}\left(B_{a}\right)$ of the $\mathrm{MgB}_{2}$ sample with PCS doping considerably exceeds those of the $\mathrm{MgB}_{2}$ samples with carbohydrate dopants (Fig. 1). Note, in contrast to oxygen containing carbohydrates, PCS doping does not introduce excessive oxidation effects (e.g., for $\mathrm{Mg}$ ), which result in unwanted sediments around $\mathrm{MgB}_{2}$ grains, reducing the current flow. The level of $\mathrm{MgO}$ is 7, 7, 12, and $18 \mathrm{wt} \%$ for pure, PCS, malic acid, and the sugar doped $\mathrm{MgB}_{2}$ samples, respectively. Note, the higher level of $\mathrm{MgO}$ in the sugar doped sample than in the malic doped sample may be due to both, higher level of oxygen in this compound and water used during the liquid mixing. There could be about $20 \%$ variation of $\mathrm{MgO}$ content in pure $\mathrm{MgB}_{2}$ samples, depending on preparation route (liquid or dry mixing) at the same conditions and environment. In addition, the large amount (11 wt \%) of $\mathrm{Mg}_{2} \mathrm{Si}$ impurities in PCS doped sample introduce an additional level of lattice distortion [defects of type (i)], resulting in enhanced $J_{c}\left(B_{a}\right)$ at low temperature $(5 \mathrm{~K})$, and these act as pinning centers themselves at higher temperatures, explaining the excellent $J_{c}\left(B_{a}\right)$ performance in PCS doped $\mathrm{MgB}_{2}$ sample at $20 \mathrm{~K}$ (Fig. 1), which far exceeds those of malic acid and sugar doped samples.

Carbon-based doping results in the reduction of the $a$-lattice parameter ( $\Delta a$ in Fig. 3$)$ due to the $\mathrm{C}$ substitution for $\mathrm{B}$ sites in the $\mathrm{MgB}_{2}$ crystal lattice. ${ }^{13}$ Generally, the larger the $\Delta a$ value, the higher is the level of $\mathrm{C}(x)$ substituted for $\mathrm{B}$ in $\mathrm{MgB}_{2}$, producing a denser network of microstructural defects [type (i)] crucial for enhancement of current-carrying ability in the $\mathrm{MgB}_{2-x} \mathrm{C}_{x}$ superconductor. The results in Fig. 3 show that the liquid mixing approach promotes the enhanced incorporation of $\mathrm{C}$ on $\mathrm{B}$ sites in the $\mathrm{MgB}_{2-x} \mathrm{C}_{x}$ crystal lattice during the sintering when compared to the conventional drymixed samples prepared with SiC (Ref. 14) and C (Ref. 15) nanodopants. 


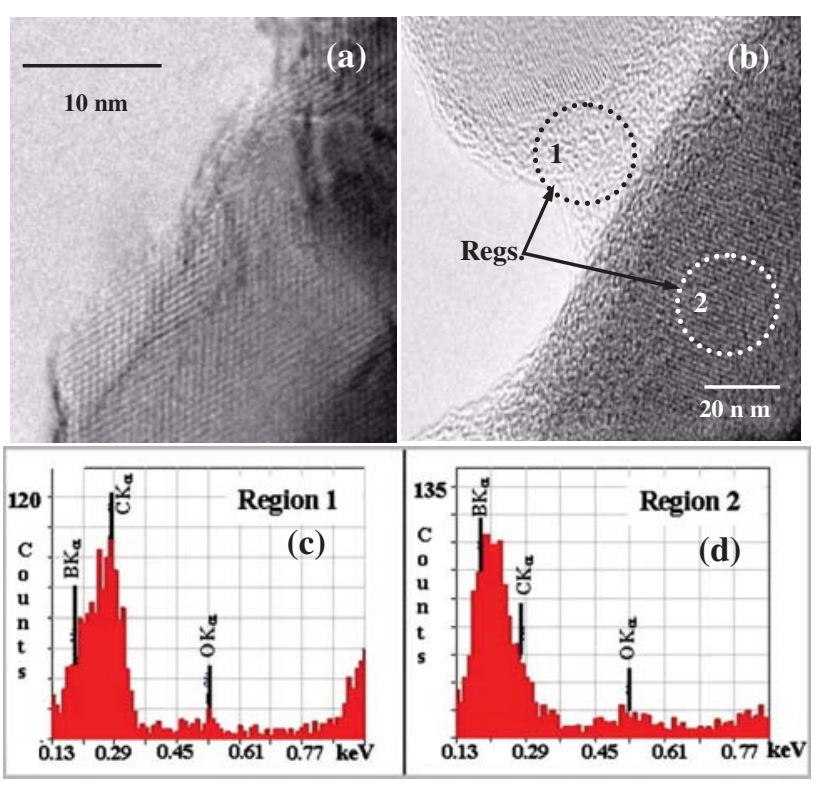

FIG. 4. (Color online) TEM images of crystalline boron nanoparticles: (a) as received; (b) coated by an amorphous carbon nanolayer. [(c) and (d)] EDS spectra obtained from regions 1 and 2 in (b).

To clarify the role of the liquid mixing approach for promoting $\mathrm{C}$ substitution in the $\mathrm{MgB}_{2}$ lattice (Fig. 3) and enhancing $J_{c}\left(B_{a}\right)$ of $\mathrm{MgB}_{2}$ with the dopants studied (Fig. 1), TEM analysis of boron nanoparticles after liquid mixing with C-based compounds was performed. Crystalline boron was used in order to boost the contrast between B and amorphous $\mathrm{C}$ in TEM observations. First, the surface of the reference crystalline boron nanoparticles (as obtained from a supplier) was examined. The lattice fringes associated with crystalline boron continue all the way along to the edge of the sample, consistent with the presence of clean crystallites, free from any significant surface contamination [Fig. 4(a)].

Next, TEM observation was performed on the boron + sugar slurry, which was dried after liquid mixing of these elements in distilled water. An amorphous layer, 10-20 nm thick, was consistently observed at the edges of the crystalline B-particles [Fig. 4(b)], and analyzed using EDS. The EDS spectrum associated with region 1 reveals a high amount of carbon (at an energy of $\sim 0.29 \mathrm{keV}$ ) [Fig. 4(c)], whereas the spectrum associated with region 2 (at $\sim 0.18 \mathrm{keV}$ ) indicates that boron is the dominant element in this region [Fig. 4(d)]. Due to the low count rate generated by the small areas $(\sim 25 \mathrm{~nm})$, it was difficult to precisely evaluate the concentration of $\mathrm{B}$ and $\mathrm{C}$ elements in these regions. However, the TEM observations supported by the EDS spectra unambiguously demonstrate the formation of the carbon-rich nanolayer, which coats the B particles after liquid mixing.

The TEM images obtained for malic acid and PCS doped samples are very similar to those shown in Fig. 4, but for latter the B particles are coated by a mixture of amorphous $\mathrm{C}$ and $\mathrm{Si}$, as confirmed by EDS analysis.

This coating configuration offers the most possible homogeneity of mixing and an optimal reaction area between boron and carbon. In addition, decomposition of the studied
C-based dopants at low temperatures $\left(<300^{\circ} \mathrm{C}\right)$ assures a two-stage process: ${ }^{7}$ (i) formation of fresh carbon and (ii) subsequent $\mathrm{MgB}_{2}$ formation, which assures effective chemical doping of $\mathrm{MgB}_{2}$ superconductor by $\mathrm{C}$, and results in the dramatic enhancement of electromagnetic properties in $\mathrm{MgB}_{2-x} \mathrm{C}_{x}$ material. This process has been generalized to the so-called dual reaction model, ${ }^{2}$ which works for various combinations of multielement dopants releasing fresh carbon in the first stage (which does not necessarily involve liquid mixing).

In summary, we have demonstrated that developed liquid mixing approach results in the formation of an extremely reactive C-rich nanolayer on the surface of the boron particles. During subsequent reaction with $\mathrm{Mg}$ and B powders, this configuration promotes a higher level of carbon substitution into the $\mathrm{MgB}_{2}$ crystal lattice. This substitution generates a denser network of pinning sites and results in enhanced $J_{c}\left(B_{a}\right)$ performance at high fields. The results of this work show that the liquid mixing approach can be effectively employed for polycarbosilane doping of $\mathrm{MgB}_{2}$ superconductor, which results in the dramatic enhancement of the critical current density in this material at high fields. Moreover, the approach of liquid pretreatment is generally expected to create a nanoscale coating on host particles, independent of the liquid solution and the host particles, which would make this process extremely efficient for relevant technologies in different areas of science.

This work is financially supported by the Australian Research Council.

${ }^{1}$ J. Nagamatsu, N. Nakagawa, T. Muranaka, Y. Zenitani, and J. Akimitsu, Nature (London) 410, 63 (2001).

${ }^{2}$ S. X. Dou, O. Shcherbakova, W. K. Yeoh, J. H. Kim, S. Soltanian, X. L. Wang, C. Senatore, R. Flükiger, M. Dhalle, O. Husnjak, and E. Babic, Phys. Rev. Lett. 98, 097002 (2007).

${ }^{3}$ S. X. Dou, A. V. Pan, S. Zhou, M. Ionescu, X. L. Wang, J. Horvat, H. K. Liu, and P. R. Munroe, J. Appl. Phys. 94, 1850 (2003).

${ }^{4}$ A. Matsumoto, H. Kumakura, H. Kitaguchi, B. J. Senkowicz, M. C. Jewell, E. E. Hellstrom, Y. Zhu, P. M. Voyles, and D. C. Larbalestier, Appl. Phys. Lett. 89, 132508 (2006).

${ }^{5}$ A. Yamamoto, J. Shimoyama, S. Ueda, I. Iwayama, S. Horii, and K. Kishio, Supercond. Sci. Technol. 18, 1323 (2005).

${ }^{6}$ J. M. Rowell, Supercond. Sci. Technol. 16, R17 (2003).

${ }^{7}$ S. Zhou, A. V. Pan, D. Wexler, and S. X. Dou, Adv. Mater. 19, 1373 (2007).

${ }^{8}$ J. H. Kim, S. Zhou, M. S. A. Hossain, A. V. Pan, and S. X. Dou, Appl. Phys. Lett. 89, 142505 (2006).

${ }^{9}$ H. P. Martin, Fresenius' J. Anal. Chem. 349, 160 (1994).

${ }^{10}$ R. H. T. Wilke, S. L. Bud'ko, P. C. Canfield, D. K. Finnemore, R. J. Suplinskas, and S. T. Hannahs, Phys. Rev. Lett. 92, 217003 (2004).

${ }^{11}$ Y. Zhu, A. Matsumoto, B. J. Senkowicz, H. Kumakura, H. Kitaguchi, M. C. Jewell, E. E. Hellstrom, D. C. Larbalestier, and P. M. Voyles, J. Appl. Phys. 102, 013913 (2007).

${ }^{12}$ O. V. Shcherbakova, A. V. Pan, J. L. Wang, A. V. Shcherbakov, S. X. Dou, D. Wexler, E. Babic, M. Jercinovic, and O. Husnjak, Supercond. Sci. Technol. 21, 015005 (2008).

${ }^{13}$ M. Avdeev, J. D. Jorgensen, R. A. Ribeiro, S. L. Bud'ko, and P. C. Canfield, Physica C 387, 301 (2003).

${ }^{14}$ O. V. Shcherbakova, A. V. Pan, D. Wexler, and S. X. Dou, IEEE Trans. Appl. Supercond. 17, 2790 (2007).

${ }^{15}$ W. K. Yeoh, J. H. Kim, J. Horvat, X. Xu, M. J. Qin, S. X. Dou, C. H. Jiang, T. Nakane, H. Kumakura, and P. Munroe, Supercond. Sci. Technol. 19, 596 (2006). 